\title{
Peran Alex Evert Kawilarang Dalam Menumpas DI/TII di Jawa Barat
}

\author{
Abdul Fatah Miftahudin, Ading Kusdiana \\ Fakultas Adab dan Humaniora, Universitas Islam Negeri Sunan Gunung \\ Djati Bandung \\ Email : alfatihmiftahudin1507@gmail.com
}

\begin{abstract}
The Darul Islam Movement / Indonesian Islamic Army (DI / TII) is a movement that emerged from dissatisfaction with the "Renville" agreement which impacted on TNI and army troops who had to migrate from West Java. on August 7, 1949 S. M. Kartosuwirjo as the leader declared the establishment of the Islamic State of Indonesia (NII) with its central position in West Java, especially in the East Priangan area. This made things even more difficult to control when on 19 December 1948 the Dutch reneged on the Renville Agreement and attacked the Indonesian capital in Yogyakarta, the Second War of Independence broke out, so this triggered the return of troops who migrated to their troops in West Java, but when it arrived at their troops were welcomed like enemies, finally a war broke out between three camps namely the TNI, Darul Islam and the Dutch troops. to the point where on December 27, 1949 the Dutch recognized the sovereignty of the Republic of Indonesia but DI / TII remained in principle wanting to establish a State based on Islamic sharia. The government finally held diplomacy but it did not find any bright spot so the government took the road to dissolve the DI / TII movement by force. Colonel AE Kawilarang, who at that time served as Commander of the Army and Territory III / West Java and was responsible for restoring security and peace in the region of West Java, thus the central government issued an Order to carry out "Operation Merdeka" in an effort to disperse DI / TII to re-lap Motherland.
\end{abstract}

Keywords: DI/TII, Kawilarang, Supperssion DI/TII 


\section{Pendahuluan}

Alex Evert Kawialrang dilahirkan pada tanggal 23 februari 1920 dari pasangan A. H. H. Kawilarang dan Nelly Betsy Mogot. Ayah Kawilarang adalah seorang tentara KNIL sejak tahun 1910 dan menjadi opsir pada 1913, Kawilarang adalah anak ke-4 dari 4 bersaudara yang ketiga kakaknya merupakan perempuan dan kawilarang satu-satunya anak laki-laki. Kehidupan masa kecil Kawilarang telah dikenalkan pada dunia militer dimana kawilarang sudah tahu pekerjaan ayahnya yang seorang KNIL dan inilah yeng membentuk sikap Kawilarang sekaligus membuat Kawilarang untuk bercita-cita menjadi tentara, hal ini mendapat dukungan dari kedua orangtuanya. ${ }^{1}$

Pindah tugas merupaka hal yang sudah sering dilakukan oleh keluarga Kawilarang mengingat bahwa ayah Kawilarang merupakan seorang KNIL yang harus siap dipindahkan kemanapun dan kapanpun, hal ini membuat Kawilarang susah untuk mendapatkan teman dan harus beradapatasi dengan lingkungan barunya, ketika orangtuanya bertugas di Jatingaleh (Semarang) Kawilarang sudah memasuki usia sekolah, saat itu ia dimasukkan ke sekolah rendah Europeesche Lagere School (ELS=SD) tapi Kawilarang bisa menuntaskan sekolahnya itu di Cimahi, saat orangtuanya bertugas di daerah tersebut sebagai Komandan Bataliyon IX KNIL.

Kemudian Kawilarang memilki kesempatan untuk melanjutkan pendidikannya di HBS-V ${ }^{2}$ (Hogere Burger School = SMP dan SMA selama lima tahun) di Bandung. Sejak di HBS Kawilarang banyak perkembangan dalam berbagai bidang terutama olahraga adapun olahraga yang Kawilarang kembangkan diantaranya senam, hockey, anggar, renang, tenis dan permainan polo air. Hal ini membuat fisik Kawilarang terlatih dan membentuk karakter yang kuat.

Setelah menamatkan HBS-V pada tahun 1940 Kawilarang langsung mendaftarkan dirinya, mengikuti seleksi dan diterima di CORO (Corp Opleiding Reserve Officieren $)^{3}$ perjalanan Kawilarang dalam dalam menempuh pendidikan di CORO sudah mencapai tingkat akhir sehingga

${ }^{1}$ Hikmat Israr, Kolonel A. E. Kawilarang Panglima Pejuang \& Perintis Kopassus (Jakarta: Asmi Publishing, 2010), 9.

2 Gedung HBS bandung saat ini dikenal sebagai SMAN 3 dan SMAN 5 Jl. Belitung Bandung.

${ }^{3}$ Korps pendidikan perwira-perwira cadangan. 
terjadi penyeleksian kembali untuk bisa melanjutkan pendidikannya, setelah begitu lama melewati seleksi akhirnya sampailah pada saat pengumuman siapa saja yang diterima dan tidak, keberuntungan ternyata berpihak kepada Kawilarang dan pada tahun 1941 Kawilarang dinyatakan lulus seleski dan diterima di KMA (Koninklijke Militaire Academie). ${ }^{4}$

Adapun pemuda-pemuda Indonesia yang lulus dan dipersiapkan untuk jadi perwira infantry adalah : A.H. Nasution, Aminin, Rachmat Kartakusuma, Mantiri Liem lking Ien, Lim Kay Hoen, dengan Kawilarang berjumlah 7 orang. ${ }^{5}$ Pendidikan yang ditempuh di KMA sangatlah terasa akan diskriminasi yang dilakukan oleh pihak Belanda terhadap pribumi ketika pemberian oenghargaan tidak ada satupun dari pribumi yang mendapakan mahkota emas meskipun dikatakan layak tetap saja dari pribumi hanya bisa mendapatkan mahkota perak. Namun ditengah berlangsungnya pendidikan KMA telah tersebar berita bahwa telah pecah Perang Pasifik ini terjadi pada hari Senin, 8 Desember 1941 sehingga berdampak pada alur pendidkan di KMA situasi ini pun semakin sulit dan dianggap genting serta membuat pendidkan harus dipindahkan sementara ke Garut menempati Hotel Papandayan namun hal ini tidak berlangsung lama yang pada akhirnya pendidikan di KMA harus dihentikan dipertengahan jalan dan para taruna langsung ditugaskan ke lapangan dan masuk keberbagai kesatuan KNIL guna menghadapi serbuan tentara Jepang.

Indonesia dalam posisi yang sangat sulit karena dari luar dan dalam mendapat serangan yang dipastikan mempengaruhi roda pemerintahan dan pengelolaan setiap daerahnya. Dalam perang kemerdekaan I dan II, Indonesia sudah sangat dalam menumpas penjajahan yang dilakukan oleh Belanda dan Jepang, ditambah munculnya gerakan yang ingin mendirikan Negara di dalam Negara yang berlandaskan hukum Islam. Gerakan Darul Islam/Tentara Islam Indonesia merupakan gerkan yang muncul atas ketidakpuasaan terhadap oemerintah pusat dalam berdiplomasi dengan pihak Belanda, hal ini terjadi ketika perjanjian Renville yang pada saat itu semua tentara dan lasykar harus hijrah dari Jawa Barat, tapi Belanda secara terangterangan mengkhianati perjanjian itu dengan menyerang Ibu Kota Indonesia yaitu Yogyakarta.

\footnotetext{
${ }^{4}$ Akademi Militer Kerajaan.

${ }^{5}$ Israr, Kolonel A. E. Kawilarang Panglima Pejuang \& Perintis Kopassus, 23.
} 
Akhirnya dari ketidakpuasan ini munculah gerkan yang menentang pemerintah pusat dengan cara ingin mendirikan Negara baru dd dalam Negara. DI/TII yang dipimpin oleh Kartosuwirjo dan bertempat di Daerah Priangan. Kawilarang yang pada saat itu menjabat sebagai Panglima Tentara dan Teritorium III/ Jawa Barat harus menghadapi tantangan yang bersumber dari dalam atau intern. Kawilarang mendapat perintah langsung agar segera melaksanakn pembubaran secara paksa DI/TII dan mengembalikannya ke pangkuan NKRI.

Sebenarnya DI/TII muncul diberbagai daerah tapi yang paling mencolok dan memiliki pengikut yang begitu besar dan terkenal hanyalah 3 daerah diantaranya Jawa Barat yang dipimpin oleh Sekarmadji Maridjan Kartosuwirjo, di Sulawesi Selatan yang dipimpin oleh Kahar Muzakar dan di Aceh dipimpin oleh Daud Beureuh.

\section{Metode Penelitian}

Langkah-langkah yang digunakan dalam penelitian ini yaitu melalui metode sejarah dan menggunakan penelitian deskriptif analisis, Sebagai cara untuk memaparkan kondisi transportasi haji masa Kolonial, maka langkahlangkah penelitiannya sebagai berikut:

\section{a. Heuristik}

Langkah pertama dalam penelitian ini ialah mengumpulkan sumbersumber sejarah. ${ }^{6}$ Pada tahapan ini merupakan tahapan pengumpulan data dan kegiatan untuk menghimpun informasi yang dapat digunakan sebagai sumber data. ${ }^{7}$ Dalam hal ini para sejarawan berusaha untuk mengumpulkan sumber-sumber sejarah, selain itu juga sumber sejarah disebut juga sebagai data sejarah, adapun yang dimaksud adalah sumber yang telah dikumpulkan harus sesuai dengan jenis sejarah yang akan ditulis. ${ }^{8}$

Sumber berupa koran:

a) Permesta Dibubarkan Diseluruh Nusa Tenggara (Antara, 31 Maret 1958).

Sumber berupa buku :

\footnotetext{
${ }^{6}$ Daliman A, Metodologi Penelitian Sejarah (Yogyakarta: Ombak, 2012), 51.

${ }^{7}$ E. Kosim, Metode Sejarah Asas Dan Proses (Bandung: UNPAD, 1984), 30.

${ }^{8}$ kuntowijoyo, Pengantar Ilmu Sejarah (Yogyakarta: Bentang Pustaka, 2005), 95.
} 
Peran Alex Evert Kawilarang dalam Menumpas DI/TII di Jawa Barat |Abdul Fatah Miftahudin, Ading Kusdiana

a) Nasution, A.H. 1978. Sekitar Perang Kemerdekaan Indonesia: Agresi Militer Belanda I jilid 5. Bandung: Disjarah-AD \& Penerbit Angkasa.

b) Nasution, A.H. 1988. Memenuhi Panggilan Tugas, Jilid 9: Masa Pemberontakan PKI 1948 Jakarta: PT Gunung Agung.

c) Nasution, A.H. 1978. Sekitar Perang Kemerdekaan Indonesia: Agresi Militer Belanda I jilid 5. Bandung: Disjarah-AD \& Penerbit Angkasa.

d) A. H. Nasution. 1968. Sejarah Perjuangan Nasional di bidang bersenjata: Mega Bookstore, Jakarta.

\section{b. Kritik}

Dari sumber sejarah di atas dasar berbagai alasan atau syarat. Setiap sumber harus dinyatakan terlebih dahulu autentik dan integritasnya. Saksi mata atau penulis itu harus diketahui sebagai orang yang dapat dipercaya (credibe). ${ }^{9}$ Dalam hal ini ada dua cara dalam mengkritik sebuah sumber, pertama kritik Ekstern dan kedua kritik intern.

Setelah melakukan kritik ekstern dan kritik intern terhadap sumber yang terkumpul mengenai pembahasan tentang Peran Alex Evert Kawilarang dalam Menumpas Di/TII di Jawa Barat maka sumber tersebut dikelompokan menjadi sumber primer dan sumber sekunder.

Sumber Primer

1. Permesta Dibubarkan Diseluruh Nusa Tenggara (Antara, 31 Maret 1958). Koran ini diterbitkan pada tahun saat kejadian maka dari itu termasuk sumber primer, sebagai tambahan Koran ini adalah cikal bakal dari berita kembalinya seluruh pemberontak kepangkuan NKRI.

Buku:

Nasution, A.H. 1978. Sekitar Perang Kemerdekaan Indonesia: Agresi Militer Belanda I jilid 5. Bandung: Disjarah-AD \& Penerbit Angkasa.Nasution, A.H. 1988. Memenuhi Panggilan Tugas, Jilid 9: Masa Pemberontakan PKI 1948 Jakarta: PT Gunung Agung.Nasution, A.H. 1978. Sekitar Perang Kemerdekaan Indonesia: Agresi Militer Belanda I jilid 5. Bandung: Disjarah-AD \& Penerbit Angkasa dan A. H. Nasution. 1968. Sejarah Perjuangan Nasional di bidang bersenjata. Mega Bookstore. Jakarta.

9 Helius Sjamsudin, Metodologi Sejarah, Cetakan Ke (Yogyakarta: Penerbit Ombak, 2016), 84. 
dari keempat buku diatas merupakan karangan dari orang yang telah menjadi saksi sekaligus pelaku dan sahabat dari Kawilarang dari sejak masuk KMA maka hal ini memperkuat bahwa sumebr ini sebagai sumber Primer.

\section{c. Interpretasi}

Langkah selanjutnya yang penulis lakukan dalam penleitan sejarah ini adalah interpretasi. Interpretasi merupakan penafsiran terhadap fakta-fakta yang penulis dapatkan dari sumber-sumber yang telah melalui tahap kritik sumber yang relevan dengan kajian yang menjadi objek penelitian penulis.

Dalam bukunya Abdurahman ${ }^{10}$ menurut Kuntowijoyo interpretasi sejarah dapat dilakukan dengan menggunakan dua metode utama, yakni analisis (menguraikan) dan sintesis (menyatukan). Penulis menggunkan metode sintesis yang menurut Sjamsuddin ${ }^{11}$ menjelaskan bahwa dalam penafsiran sintesis tidak ada sebab tunggal dalam suatu peristiwa sejarah. Perkembangan dan jalannya sejarah digerakan oleh beberapa faktor dan tenaga secara bersamaan dan menjadikan manusia sebagai pemeran utamanya. Penulis melakuakan penafsiran sintesis karena sikap dan pandangan A.E Kawilarang hanya dipengaruhi berbagai faktor, faktor tersebut muncul dari politik, ekonomi, dan latar berlakang kehidupan A.E Kawilarang. Selain itu penulis menggunakan metode penafsiran sintesis untuk menyatukan berbagai fakta yang telah diverifikasi untuk menyusun interpretasi yang kronologis dan dapat dipertanggung jawabkan. Dalam melakukan interpretasi, fakta-fakta harus disusun dan dihubungkan sehingga menjadi sutau kesatuan yang selaras.

\section{d. Historiografi}

Tahapan Historiografi merupakan tahapan berupa kegiatan penulisan hasil penafsiran atas fakta-fakta dan usaha merekontruksi masa lampau untuk memberikan jawaban atas masalah-masalah yang telah dirumuskan di atas. Dengan demikian historiografi adalah tahapan lanjutan dari interpretasi yang kemudian hasilnya dituliskan menjadi kisah yang menarik. Pada tahapan historiografi ini, hasil penafsiran atas fakta-fakta itu kita tuliskan menjadi suatu kisah sejarah yang selaras. Dengan demikian tahapan yang diatas telah disusun dengan sebaiknya. Dengan melihat tahapan-tahapan ini tidaklah

${ }^{10}$ D Abdurahman, Metodologi Penelitian Sejarah (Yogyakarta: Ar- Ruzz media, 2007), 70 .

${ }^{11}$ Sjamsudin, Metodologi Sejarah, 117. 
mengherankan apabila dikatakan bahwa kerja seorang sejarawan untuk menghasilkan sebuah hasil karya ilmiah yang bernilai historis.

\section{Hasil dan Pembahasan}

\section{A. Biografi S. M. Kartosuwiryo}

Sekarmaji Marijan Kartosuwiryo (S. M. Kartosuwiryo) merupakan pimpinan dari DI/TII yang dilahirkan di suatu desa yang bernama Sulung Kabupaten Rembang, Jawa Tengah pada tanggal 7 Pebruari 1950. Ayahnya bernama Kartosuwiryo yang bekerja sebagai Mantri Kehutanan. ${ }^{12}$ Jejak langkah Kartosuwiryo dibidang pendidikan dimulai dari sekolah dasar (Tweede Islandsche School), yang kemudian pindah ke Holand Inlandsche School (HIS) lalu pindah ke Europeesch Lagere School (E.L.S). Kemudian setelah menamatkan pelajarannya di Hogere Burgerlijk School (HBS) akhirnya melanjutkan pelajarannya di Nederlands Indische Artsen School (NIAS), Surabaya. Namun keburu dikeluarkan karena diketahui aktif melaksanakan kegiatan politik. Kartosuwiryo setelah dikeluarkan menjadi guru swasta di Bojonegoro kemudian pengaruh dan pemikiran politik membuat dirinya tertarik dan salah satu yang menarik perhatiannya yaitu Sarikat Islam yang didirikan oleh Haji Umar Said Cokroaminoto, dan dia di bimbing oleh pimpinan SI untuk belajar mengenai strategi politik dan perjuangan di dalam partai sehingga ia pernah diangkat menjadi sekretaris pribadi.

Untuk jejak langkah Kartosuwiryo dalam pembentukan DI/TII sebenarnya sudah muncul ketika Kartosiwuryo memperiapkan kaderkadernya melalui Institut Supah. ${ }^{13}$ Ia merupakan tokoh politik yang pintar memainkan irama sehingga tidak mudah untuk mengetahui arah pemikiran dan tujuannya dalam pembentukan embrio DI/TII, dalam masa pemerintahan jepang Kartosuwiryo menyesuaikan irama politiknya melalui pelatihan para pemuda yang tergabung dalam Hisbullah dan Sabilillah yang belajar di Institut Supah dilatih secara kemiliteran dengan tujuan utamanya para pemuda ini menjadi penyokong utama dalam merealisasikan idea mendirikan "Negara Islam Indonesia".

12 Amak Syarifudin, Kisah Karosuwiryo Dan Menyerahnya (Surabaya: Orip, 1965), 5.

13 Gedung sekolah yang dibangun antara Malangbong-Balubur Limbangan-Garut, meliputi area seluas 4 Hektar. 
Kita ketahui bersama bahwa pada masa Jepang ada sebuah partai politik yang bernama Majelis Syuro Muslimin Indonesia (Masyumi), yang secara kebetulan Kartosuwiryo merangkap jabatan sebagai sekretaris Masyumi yang didirakan pada masa Jepang tapi ketika Jepang menyerah Kartosuwiryo mendirikan Masyumi dengan gaya baru yang tidak meneruskan tradisi Jepang. ${ }^{14}$

\section{B. Pergerakan Negara Islam Indonesia (Sekarang dikenal DI/TII)}

Awal mula pembangkangan Kartosuwiryo terjadi pada tahun 1948 yang menyatakan dirinya sebagai pimpinan dari Darul Islam sejak Maret 1948. Ia bersama-sama dengan laskarnya bergerilya melawaan Belanda dan kemudian pasukan-pasukan TNI terutama dari Divisi Siliwangi. Ketika dirasanya bahwa kedudukannya dengan laskarnya telah kuat dengan terangterangan ia memproklamasikan "Negara Islam Indonesia (NII)" dan laskarnya disebut "Tentara Islma Indonesia (TII)". Hal itu merupakan realisasi dari cita-citanya yang telah diwujudkan berpuluh tahun sebelumnya.

Dalam tahap pertama Kartosuwiryo berjuang dengan menggunakan kedok mempertahankan proklamasi akan tetapi lama-kelamaan perjuangan itu berubah mengarah kepada tujuan utamanya mendirikan Negara islam Indonesia, pengaruhnya terasa kian membesar terutama di daerah Jawa Barat yang terpusat pada daerah-daerah dan desa-desa yang memang sebagian besar beragama Islam.

Jika dilihat secara Geografis dan Sosial wilayah Jawa Barat merupakan wilayah strategis untuk menggalang kekuatan secara besar-besaran demi terbentuknya Negara Islam Indonesia. Wilayah Jawa Barat memiliki banyak hutan dan tanaman yang dapat digunakan sebagai makanan pokok untuk bertahan hidup selama persiapan untuk mencapai tujuannya selain itu juga sudah banyak perkebunan yang dapat digunakan untuk pertahanan dikala DI/TII diserang oleh pasukan TNI, sebenarnya Kartosuwiryo sudah memperkirakan kejadian dimana suatu dia diburu bersama kelompoknya karena sudah bertolak belakang dengan cita-cita proklamasi.

Selain itu kehidupan masyarakat yang minim pendidikan membuat mereka mudah di provokator dengan menggunakan kedok agama sebagai senjata terampuh untuk menghimpun kekuatan. Selain dari pada hal tersebut diatas masyarakat Jawa Barat masih percaya terhadap "Uga-Uga" atau

14 Kartosuwiryo menduduki jabatan sekretaris I samapi Proklamasi Kemerdekaan Indonesia ia aktif dalam Partai Masyumi. 
ramalan. Salah satu diantara Uga tersebut ialah Uga "Ratu Adil". Mereka mempercayai bahwa suatu ketika akan datang Ratu Adil di Jawa Barat yaitu seorang Kepala Negara yang melaksanakan Hukum Islam. ${ }^{15}$

Kemudian dilihat dari faktor politik pemerintahan pusat telah mengadakan perjanjian dengan Belanda yaitu Perjanjian Renville yang mengharuskan para tentara dan lascar-laskar harus hijrah ke Jawa Tengah dan meninggalkan Jawa Barat. dalam pandangan Kartosuwiryo pemerintah pusat telah menjual Negara kepada Belanda oleh sebab itu Kartosuwiryo menolak untuk hijrah dan bertahan di Jawa Barat. Mereka mengatakan bahwa Republik Indonesia diibaratkan rumah yang tiang-tiangnya sudah rapuh semuanya, karena pemerintah dibina oleh orang-orang yang tidak becus dan korup lagipula sebenarnya Kartosuwiryo tidak percaya dengan pemerintah pusat karena sudah di dominasi oleh golongan komunis. ${ }^{16}$

Ketika para pertinggi Negara, TNI dan lascar-laskar berada di Jawa Tengah hal ini dimanfaatkan oleh Karosuwiryo dengan baik, dengan mengadakan konferensi dibeberapa daerah diantaranya Cisayong, Cirebon dan Cijoho hal ini bertujuan untuk merealisasikan dan melebarkan sayap keberbagai daerah.

Sebenarnya banyak dari kalangan militer yang tidak setuju dengan penanda tanganan perjanjian Renville, bukan tanpa alasan menurut pihak militer terutama Siliwangi daerah yang sudah ditempati dan dibina begitu saja diserahkan ke pihak musuh yang secara taktis untuk menenruskan perjuangan sangat menguntungkan, meskipun begitu tentara adalah rakyat yang tetap harus patuh pada keputusan pemerintah pusat, dengan hijrahnya pasukan Siliwangi maka di Jawa Barat terjadi kekosongan yang berhasil dimanfaatkan oleh Kartosuwiryo dalam mencapai cita-citanya mendirikan Negara Islam Indonesia.

Strategi bususk Belanda untuk memecah persatuan dan kesatuan rakyat Indonesia sedikit berhasil, karena dalam perjanjian ini ada bebrapa hal yang berhasil dianalisis, pertama perjanjian Renville adalah strategi dibidang politiknya, kedua strategi dibidang militernya yaitu Belanda kembali melanjutkan pengepungan, penyerangan dan penyebarluasan daerah jajahan,

15 Sayarif Hidayat bersama Wawancara Pada Tanggal 18 Januari 1971 di Bandung.

${ }^{16}$ Wawancara bersama Nasuhi Tanggal 15 Agustus 1971 Di Bandung. 
ketiga dalam bidang ekonomi, Belanda melakukan Blokade yang luas dan ketat terhadap Negara Indonesia. ${ }^{17}$

Salah satu faktor yang menyebabkan rakyat Jawa Barat menaruh simpati dan menyokong gerakan gerombolan ini ialah karena keadaan ekonomi yang telah mencekam rakyat di daerah itu, sejak jaman penjajahan Belanda, jaman penjajahan Jepang dan tahun-tahun pertama berdirinya Republik Indonesia. Tuan-tuan tanah yang menghisap rakyat Jawa barat sejak jaman penjajahn Belanda dan Jepang kemudian diterusakan sampai jaman kemerdekaan, dipandangnya sebagai faktor utama yang menimbulkan rasa tidak puas dikalanagn rakyat perani dan rakyat pedusunan pada umumnya. Kemudian timbulnya DI yang pada waktu itu mempunyai modal politik dan materil yang cukup besar dipandang oleh rakyat sebagai golongan atau kekuatan baru yang dapat menolong mereka dari penderitaan dan perasaan tidak puas tadi. ${ }^{18}$

Jika dianalisis dari pernyataan di atas maka jelas Indonesia pada waktu itu mengalami krisis kepercayaan terhadap pemerintah pusat apalagi penjajah yang selalu membuat rakyat menderita, sehingga ketika ada sebuah organisasi yang berkedok agama dan memiliki dana yang cukup besar untuk membuat rakyat percaya akan hadirnya "Ratu Adil". Dalam hal ini rakyat yang sudah tidak percaya terhadap pemerintah pusat menjadi salah satu pemasok kekutan untuk mewujudkan cita-cita mendirikan Negara Islam Indonesia. Maka pembahasan selanjutnya adalah proses dari pembubaran dan penumpasan DI/TII di Indonesia.

\section{Operasi Penumpasan DI/TII oleh A. E. Kawilarang}

Pada tanggal 27 Desember 1949, ${ }^{19}$ dengan pengakuan kedaulatan RI tersebut pemerintah berharap DI membubarkan diri dan kembali mendukung pemerintah, namun hal itu tidak terlaksana, sehingga dalam upaya menumpas gerombolan DI pimpinan Kartosuwiryo di Jawa Barat, mulai tanggal 17 Agusutus 1950 pemerintah melancarkan "Operasi Merdeka". Akan tetapi dalam pelaksanaan operasi tersebut belum menunjukan keseriusan atau dilakukan dengan setengah-setengah, karena pemerintah

17 A. H. Nasution, Sejarah Perjuangan Nasional Di Bidang Bersenjata (Jakarta: Mega Bookstore, 1968).

18 Pinardi, Sekarmaji Marijan Kartosuwiryo (Jakarta: PT BP Aryaguna, 1964), 152.

19 A.H Nasution, Memenuhi Panggilan Tugas, Jilid 3: Masa Pancaroba Pertama (Jakarta: PT Gunung Agung, 1983), 61. 
masih mengharapkan upaya damai agar Kartosuwiryo serta pengikutnya meletakan senjata dan menyadari kekeliruannya. ${ }^{20}$

Untuk maksud damai tersebut Perdana Menteri Natsir pernah mengirimkan utusan pribadinya, yakni Wali Alfatah guna mengajak Kartosuwiryo berdamai. Namun utusan tersebut ditolak oleh Kartosuwiryo, dan dia menuntut agar diadakan perundingan dengan utusan kalangan tertinggi dalam pemerintah.

Karena kebijakan pemerintah yang setengah-setengah tersebut dan tidak dilaksanakannya "Operasi Merdeka" secara tegas sebagaimana yang sudah direncanakan oleh pimpinan Angkatan Perang. Dalam situasi yang demikian itu Kolonel A. E. Kawilarang mendapat perintah sebagai Panglima Tentara dan Teritorium III/Jawa Barat yang notabene bertanggung jawab terhadap pemulihan keamanan dan ketentraman wilayah Jawa Barat, terutama dari kekacauan gerombolan bersenjata yang menamakan dirinya DI/TII. ${ }^{21}$

Karena gerombolan DI/TII pada saat itu memiliki kekuatan yang cukup besar, maka perhatian Kawilarang tertuju pada kemampuan pasukan TNI, baik organik Siliwangi maupun yang di-BP-kan dari TT-V/ Brawijaya. Dalam pengamatannya saat itu gerakan yang dilakukan pasukan TNI masih kurang sekali, lamban, sehingga tidak efektif dalam pelaksanaan tugas. Oleh karena itu, Kawilarang yang memang tentara lapangan, merasa perlu langsung turun ke medan operasi untuk memperbaiki gerakan pasukannya. ${ }^{22}$

Walaupun Kolonel A.E. Kawilarang seorang Panglima, namun ia selalu dekat dengan pasukannya, bahkan di luar dinas bawahanya boleh saja memanggilnya dengan sebutan akrab "Alex" tanpa sedikitpun menjatuhkan wibawanya sebagai seorang Panglima. Dalam Operasi penumpasan DI/TII, tidak sekali dua kali Kawilarang terlibat langsung memimpin anak buahnya dalam pertempuran. ${ }^{23}$

Suatu hari Kawilarang mendapat laporan bahwa satu peleton di bawah Komando Sektor Cianjur pimpinan Mayor Achmad Wiranartakusumah dipukul mundur oleh kira-kira 600 orang DI/TII yang bersenjatakan

\footnotetext{
${ }^{20}$ Israr, Kolonel A. E. Kawilarang Panglima Pejuang \& Perintis Kopassus, 232.

21 Israr, 233.

22 Nasution, Memenuhi Panggilan Tugas, Jilid 3: Masa Pancaroba Pertama, 62.

${ }^{23}$ Israr, Kolonel A. E. Kawilarang Panglima Pejuang \& Perintis Kopassus, 234.
} 
sedikitnya 10 brengun. Tepatnya di daerah pegunungan mulai dari Pasir Angin sampai Pasir Kuda. ${ }^{24}$

Mendapat laporan tersebut Kawilarang langsung menyiapakan pasukannya yang terdiri dari Mayor Mursjid, Kapten Soepomo, Letda Yogie SM, beberapa orang dari pasukan komando dan sekitar peleton Yon 330. Dengan menggunakan truk, pasukan yang dipimpin langsung Panglima Siliwangi tersebut menuju daerah air terjun Citambur di kampung Cinangka, dengan tujuan akan menyerang dari arah belakang kedudukan musuh yang saat itu berada di sekitar Pasir Kuda. ${ }^{25}$

Sayangnya sebelum sampai di Pasir Kuda, pos tinaju musuh telah mengetahui kedatangan pasukan Kawilarang, sehingga pendadakan yang direncanakan Kawilarang tidak tercapai. Selanjutnya terjadilah tembak menembak antara pasukan pimpinan Kawilarang dengan pasukan musuh yang diprediksinya langsung di bawah pimpinan Kartosuwiryo. Tembak menembak itu terjadi dari pukul 06.00 pagi sampai pukul 15.00 karena kekuatan musuh cukup besar, mereka berhasil melarikan diri. Dalam pertempuran tersebut pasukan Kawilarang cuma berhasil merebut satu senapan musuh. ${ }^{26}$

Dalam kesempatan lain, Kawilarang juga pernah ikut dalam gerakan yang dipimpin oleh Komandan Kompi Lettu Fadilah. Mereka berhasil mendapati kamp-kamp gerombolan yang baru saja ditinggalkan, yang berada di tengah-tengah pohon-pohon bambu. Dipilihnya lokasi di tengah-tengah pohon bambu tersebut oleh gerombolan DI/TII karena dari suara daun-daun bambu itu mereka bisa mendengar kedatangan pasukan TNI, sehingga mereka berkesempatan untuk melolosakan diri dari pasukan Kawilarang. ${ }^{27}$

Kawilarang dan pasukannya dalam patroli saat itu juga berhasil mencapai suatu tempat yang diduga sebagai peresembunyian Kartosuwiryo. Tetapi waktu itu pasukan Kawilarang terhalang oleh banjir besar yang menyebabkan pasukan tidak bisa menyeberang, Kawilarang tidak mau

24 Israr, 235.

25 A.H Nasution, Memenuhi Panggilan Tugas, Jilid 4: Masa Pancaroba Kedua (Jakarta: PT Gunung Agung, 1984), 75.

${ }^{26}$ Nasution, Memenuhi Panggilan Tugas, Jilid 3: Masa Pancaroba Pertama, 64.

${ }^{27}$ Israr, Kolonel A. E. Kawilarang Panglima Pejuang \& Perintis Kopassus, 236. 
mengambil resiko, sehingga Kartosuwiryo dan pasukannya yang ada diseberang sungai berhasil lolos. ${ }^{28}$

Sebagaimana diungkapkan di atas, bahwa sikap pemerintah tidak tegas dalam mengatasi persoalan DI/TII, maka operasi yang dilakukan tidak dapat berjalan dengan maksimal. Sehingga pada masa Kolonel A. E. Kawilarang menjabat Panglima Tentara dan Teritorium III/ Siliwangi, meskipun kekuatan DI/TII mulai berkurang, akan tetapi Kartosuwiryo sebagai pimpinan DI/TII tersebut belum dapat ditangkap. Barulah kemudian hari pada tanggal 4 Juli 1962 Kartosuwiryo berhasil ditangkap di Gunung Geber oleh Kompi Pimpinan Letda Suhanda dari Yon 328/ Kujang II. Saat itu yang menjadi Panglima Siliwangi adalah Brigjen Ibrahim Ajie. ${ }^{29}$

\section{Simpulan}

Berdasarkan pembahasan di atas maka dapat disimpulkan sebagai berikut:

Pertama DI/TII adalah organisasi yang didirikan oleh Sekarmadji Maridjan Kartosuwiryo dan diproklamirkan pada tanggal 7 Agustus 1949 dan memiliki tujuan untuk mendirikan Negara dalam Negara yang berlandaskan hukum Islam (Teokrasi), dan hal ini bertentangan atau bertolak belakang dengan Pancasila dan UUD 1945.

Kedua, dalam hal ini Kartosuwiryo merupakan tokoh yang hebat dan cerdas serta kritis akan kebijakan dari Pemerintah Pusat, selain itu pula Kartosuwiryo menanggap kelalaian pemerintah pusat sebagai kesempatan yang luarbiasa, sehingga ia bisa bergerak bebas di Jawa Barat dalam merealisasikan pembentukan Negara Islam Indonesia.

Ketiga Faktor ekonomi, sosial dan militer menjadi penopang dalam mengumpulkan pengikut atau anggota Negara Islam Indonesia, Perjanjian Renville bisa dipandang hanya sebagai akal bulus dari Belanda untuk melancarkan strateginya dalam menguasai Indonesia, ekonomi yang pada waktu itu telah mengalami penurunan yang cukup sulit sehingga membuat rakyat tidak percaya dengan kebijakan Pemerintah Pusat yang dianggapnya kurang tepat. Dilihat dari faktor sosialnya, Jawa Barat merupakan daerah yang kebanyakan beragama Islam dan inilah salah satu hal yang

\footnotetext{
${ }^{28}$ Nasution, Memenuhi Panggilan Tugas, Jilid 4: Masa Pancaroba Kedua, 78.

${ }^{29}$ Israr, Kolonel A. E. Kawilarang Panglima Pejuang \& Perintis Kopassus, 236.
} 
Peran Alex Evert Kawilarang dalam Menumpas DI/TII di Jawa Barat |Abdul Fatah Miftahudin, Ading Kusdiana

dimanfaatkan oleh Kartosuwiryo atau saya katakana DI/TII adalah organisasi yang berkedok agama dalam setiap gerakannya.

Keempat, dalam penumpasan yang diperintahkan Pemerintah Pusat kepada Kawilarang dianggap masih ragu-ragu dan setengah-setengah ditambah kondisi tentara yang kurang berkompeten dalam menggunakan senjata dan strategi serangan grilya dianggap menjadi faktor yang menghambat dalam penumpasan DI/TII, meskipun Kawilarang bukanlah yang menumpas DI/TII tapi ia terlibat langsung dalam operasi penumpasan DI/TII.

\section{Daftar Sumber}

Buku.

A, Daliman. Metodologi Penelitian Sejarah. Yogyakarta: Ombak, 2012.

Abdurahman, D. Metodologi Penelitian Sejarah. Yogyakarta: Ar- Ruzz media, 2007.

Israr, Hikmat. Kolonel A. E. Kawilarang Panglima Pejuang \& Perintis Kopassus. Jakarta: Asmi Publishing, 2010.

Kosim, E. Metode Sejarah Asas Dan Proses. Bandung: UNPAD, 1984.

kuntowijoyo. Pengantar Ilmu Sejarah. Yogyakarta: Bentang Pustaka, 2005.

Nasution, A. H. Sejarah Perjuangan Nasional Di Bidang Bersenjata. Jakarta: Mega Bookstore, 1968.

Nasution, A.H. Memenuhi Panggilan Tugas, Jilid 3: Masa Pancaroba Pertama. Jakarta: PT Gunung Agung, 1983.

- Memenuhi Panggilan Tugas, Jilid 4: Masa Pancaroba Kedua. Jakarta: PT Gunung Agung, 1984.

Pinardi. Sekarmaji Marijan Kartosuwiryo. Jakarta: PT BP Aryaguna, 1964.

Sjamsudin, Helius. Metodologi Sejarah. Cetakan Ke. Yogyakarta: Penerbit Ombak, 2016.

Syarifudin, Amak. Kisah Karosuwiryo Dan Menyerahnya. Surabaya: Orip, 1965.

\section{Berkas Wawancara.}

Abidin, H.Z ., wawancara tanggal 18 Januari 1971 di Bandung.

Banuarli, Sudarman (Kolonel), Wawancara tanggal 3 Januari 1947 di Bandung.

Bratamanggala, RKS, Wawancara tanggal 20 Juli 1971 di Bandung 
Peran Alex Evert Kawilarang dalam Menumpas DI/TII di Jawa Barat |Abdul Fatah Miftahudin, Ading Kusdiana

Hassan, Danu Moh (dl1), Wawancara tanggal 13 Juli 1962, di Bandung.

Hidayat, Syarip, Wawancara tanggal18 Januari 1971.

Nasuhi (Letnan Kolonel), Wawancara tanggal 15 Agustus 1971 di Bandung.

Koran.

Warta Harian Min Po, bulan Januari 1948

Warta Harian Nasional, tahun 1948

Warta harian pikiran rakyat, bulan juni-juli 1962

Antara, 31 Maret 1958. 
Peran Alex Evert Kawilarang dalam Menumpas DI/TII di Jawa Barat |Abdul Fatah Miftahudin, Ading Kusdiana 